\title{
A low tech approach to evaluating vulnerability to pollution of basement aquifers in sub-Saharan aquifer
}

\author{
N.S. Robins \\ Formerly British Geological Survey, Maclean Building, Wallingford, Oxfordshire, UK
}

\begin{abstract}
The application of quantitative approaches, such as DRASTIC, to assessing groundwater vulnerability at village scale in the weathered basement aquifer of sub-Saharan Africa is questionable. This is because the techniques are data intensive and were developed for regional scale evaluation. Deconstruction of the techniques allows the key influencing parameters to be identified. These parameters can be reviewed in terms of their likely influence on the weathered basement aquifer system and ranked as being of likely high, medium or low importance. Reassembly in the form of a scorecard, using only those parameters which can be judged subjectively in the field, produces a simple vulnerability assessment technique that can be applied at village and small town scale throughout the basement aquifer of sub-Saharan Africa. It is hoped that this tried and validated technique will provide a way forward for groundwater resource vulnerability assessment in the rural savannah lands underlain by the weathered basement aquifer system.
\end{abstract}

\subsection{INTRODUCTION}

Sub-Saharan Africa has been pre-occupied with water coverage statistics for a good few years. However, water supply is not the same as safe water supply and safe water supply coverage applies to a much smaller population of the sub-continent than overall water coverage statistics would imply. Safe water derives from a water supply that is sustainable at times of water stress and which remains potable both during a prolonged and intense rain season and progressively down 'the spiral of drought' (Calow et al., in press). In the arid and semiarid savannah lands the only sustainable water supply is groundwater because most surface waters are ephemeral and even sand river supplies may dry up periodically. Groundwater is critically important to livelihoods in these areas as it is resistant to drought, responding with a delay time behind meteoric events, be they drought or flood. However, for this same reason groundwater requires longer to recover from an extreme event than surface water, albeit seasonal water courses, but groundwater nevertheless remains the key resource over much of the weathered basement aquifer of Sub-Saharan Africa.

Not all groundwater is safe water. The sight of domestic animals drinking from standing water around a village hand pump is commonplace. But commonsense dictates that animals and their faeces should be kept away from well heads and boreholes lest they contaminate the source. Commonsense also dictates that pit latrines and soakaways should be distant from water points for the same reason, and there are a number of simple guidelines to help address these issues (e.g. MacDonald et al., 2005).

Not so easy is the problem of the vulnerability of the resource-rather than the source, or water point - to pollution from anthropogenic activities on the ground surface. Groundwater vulnerability is variously defined, but perhaps most appropriately, as the hydraulic inaccessibility of the saturated zone to the penetration of pollutants, combined with the attenuation capacity of the strata above the water table (Foster, 1998). 
Hydraulic inaccessibility depends largely on the physical properties of the substrate and its capacity to allow direct rainfall recharge to occur through it. In other words, it is the infiltration capacity of the soil cover and of the unsaturated or vadose zone. This capacity depends on the prevailing physical properties of the weathered zone, including the predominant grain size, porosity, soil cover and vegetation in addition to ground slope and aspect, and land use. Most importantly, it depends on whether there is a clay layer within the weathered zone. There are also a number of other features that may influence infiltration. For example, small scale ground topography is important because local surface ponding after rainfall creates a concentrated and prolonged zone of potential infiltration, and by pass-features such as cracks or fractures can offer a direct and rapid pathway from ground surface to the water table.

Attenuation is the physico-chemical retention or reaction of pollutants through biochemical degradation, sorption, filtration and or precipitation. A useful surrogate indicator for the chemical activity of the soil zone is the cation exchange capacity (CEC). However, CEC of soils is rarely measured and a useful secondary indicator is the amount of clay minerals that are perceived to be present in the soil (Griffiths et al., in press). Note that clay minerals are distinct from clay grade material and that rock flour does not contribute to soil CEC.

There are many techniques available to bring hydraulic inaccessibility and attenuation together to form an assessment of the vulnerability of a groundwater body. One of the more common ones is DRASTIC (Aller et al., 1987), but a variety of other methods are also available. All these methodologies are data intensive and require detailed knowledge of the soil cover and its properties and of the vadose zone and its physical and chemical properties. For the most part these data are not available for much of the basement aquifer system of Sub-Saharan Africa, and Robins et al. (2007) argue that few of the conventional approaches to vulnerability assessment used in the 'North' are readily transferable for application in the 'South'. Besides, at local scale, features such as laterite horizons and clay grade weathering products may provide some protection to the underlying regolith aquifer.

Some of the ideas from methodologies such as DRASTIC can be applied to form a robust but qualitative approach to vulnerability assessment. This approach needs to be readily applicable on the ground without the need for extensive data sets and expensive monitoring programmes, so that practitioners can make field judgements of groundwater vulnerability without recourse to intensive data gathering. New ideas can also be incorporated into the qualitative approach. One of these is weighting of the resource vulnerability according to its use, i.e. where there are people dependent on the resource for their livelihood then the resource is more valuable than locations where it is used only for marginal purposes, although even that is more valuable than groundwater that merely sustains a small dependent ecosystem.

This article describes the deconstruction of the accepted vulnerability assessment algorithms and their reassembly into a simple low-tech tick box methodology that can easily be applied in the field. The outcome of the approach is the ranking of shallow aquifers and component zones within such aquifers between highly vulnerable to weakly vulnerable pollution potential to groundwater, i.e. the converse to recharge potential. This is an easy to apply tool with which to protect groundwater resources from inappropriately located hazards, be they a pit latrine at one end of the scale to mine tailing dumps at the other. Because the assessment is measuring the converse of recharge potential it can also be used as a qualitative assessment of the available renewable resource.

\subsection{THE WEATHERED BASEMENT AQUIFER}

Recharge processes in the weathered basement aquifer are, as in all unconfined aquifers, dependent on the effective rainfall and its distribution with time. The difference with the basement aquifer is that it extends over a large area, i.e. is of regional scale, but it is extremely shallow. As a consequence, there is limited lateral transport of groundwater within it other than on a local scale, and natural discharge is invariably ephemeral, catchment scale, 
discharge to springs and seepages focussed on lower elevation ground such as valleys and other depressions. In essence, the component of the rainwater that infiltrates the ground and percolates to the water table is the sole source of groundwater in that vicinity. In some places ephemeral surface water flows and ponds lose to groundwater providing a secondary recharge source, but the scale is important as conditions can change over short distances (Adelana and MacDonald, 2008).

The typical weathering profile in the basement is a superficial lateritic layer at the top with some seasonal small scale lateral water flow. Laterite tends to be present largely in the tropical to sub-tropical regions of Africa and on the older weathering surfaces where it has not been removed by erosion (Davies and Robins, 2007). Below, may be a mottled clay layer that grades downward to a fine saprolite; a small quantity of water may be found within this layer which generally contains the water table and its zone of oscillation. The base of the fine regolith may occasionally be marked by a smectite clay horizon. The water table will fall to this level during prolonged drought. Below again is the coarse-grained saprolite, in which most groundwater is stored, the base of which commonly marks the weathering front. Limited weathering along decompression zones of horizontal fracturing may be observed within the upper parts of the underlying bedrock.

A key to understanding the performance of the weathered basement aquifer is that the thicker the regolith, or the deeper the weathering, the better developed will be the upper mottled clays. Although a thick saturated regolith is attractive from the point of view of storage, it may not be accompanied by free access via the overlying clay for potential infiltration and recharge. In addition, as seen in parts of Uganda, there is a risk of poor quality water in the thicker weathered zones in which the recharge potential is poor. Optimum resource potential, therefore, is a balance between depth of weathering and minimal development of the clay zone. In addition the occurrence of lateritic horizons near or at the surface may also inhibit recharge. But the converse to good recharge potential is good protection of the groundwater from surface pollutants, and for this the presence of a well developed clay and lateritic horizons are equally attractive.

Optimum development of the aquifer depends on locating areas of deepest weathering into which the groundwater will pond at times of water stress. These areas are likely to be the same areas that the mottled clay cover is best developed so providing a protected and sustainable source dependent on local scale lateral flow from areas where the weathering is thinner but the clay is absent or nearly so. As a consequence the evaluation of groundwater vulnerability in the aquifer can only be carried out sensibly at a local or village scale. That being said there are also indications that the age of the erosion surface dictates the depth of weathering on a regional scale, which in turn is reflected in the regional groundwater potential (Davies and Robins, 2007).

\subsection{THE GROUNDWATER VULNERABILITY DRIVERS}

Lessons can be learnt from previous vulnerability assessment campaigns and methodologies. Groundwater vulnerability maps were developed in the early 1990s for use in the UK as a planning tool and were heavily reliant on the soil zone as the key to vulnerability assessment. The maps do not consider travel time to the water table because depth to water was not then generally known on a regional basis (Robins et al., 1994). Furthermore, they were designed only for a conservative pollutant that would not degrade in the unsaturated zone (Palmer et al., 1995). The approach in Ireland, however, focussed more on the unsaturated zone (Daly and Warren, 1998) and in particular on porosity as an indicator of unsaturated permeability.

The standard assessment technique DRASTIC is a data intensive spreadsheet or GIS based assessment that relies on input from a range of datasets. These are Depth to water table, Recharge rate, Aquifer medium, Soil medium, Impact effect of the unsaturated zone 
and unsaturated hydraulic Conductivity. These data are rarely available in their entirety and invariably become subjective, besides the DRASTIC assessment only works at a larger scale than that of interest to a village community or township and disregards the human and social dimension of groundwater vulnerability. DRASTIC does indicate that the vulnerability of the basement aquifer system is low simply because recharge rates are low in strata such as weathered shales, greywackes and fractured crystalline rocks. However, a universal low does not help differentiate between land areas in which no polluting activity should take place and those where such activity would not significantly impact the groundwater body. DRASTIC, and other numerical weighting approaches to groundwater vulnerability assessment, will not, therefore, provide a useful assessment at village scale on the weathered basement aquifer.

It is, nevertheless, useful to deconstruct the standard methodologies and pull out the key controlling processes which might influence groundwater vulnerability in a basement type aquifer. Deconstruction needs to be sympathetic to the different environmental conditions in the African savannah with its shallow basement aquifer and the humid maritime lands of Western Europe where the aquifers tend to be small and compartmentalised and even the large scale generally thick continental aquifers of North America. Nevertheless, using DRASTIC and the various related methodologies as a guide, the most likely key physical processes affecting rainwater infiltration in basement strata in the semi-arid savannah lands appear to be:

- Degree and type of weathering.

- Land slope, shape and aspect.

- Vegetation and land use.

- Soil type and cover.

- Unsaturated zone properties.

- Depth to water table.

The processes promoting contaminant attenuation in the vadose zone are not quite as obvious and depend on the type of soil and rock and the types of contaminant. Attenuation is generally most active in the soil zone, where bacterial activity is greatest. The unsaturated zone, is nevertheless, of special importance as it represents a significant line of defence against pollution of groundwater. The key indicators in the unsaturated zone relate to the process of sorption, ion exchange, filtration and precipitation. Of these, ion exchange is the main overall process, the others being dependent on the nature of the pollutant as much as the nature of the unsaturated zone medium. A single value describing the potential for the medium to attract cations, the CEC, is the most useful parameter in assigning its attenuation potential. Thus CEC can be used as a meaningful surrogate for the overall attenuation processes that are likely to occur in the vadose zone.

CEC describes the process of attracting cations to a negatively charged surface-usually clay minerals. However, CEC values are commonly not available for the vadose zone and not universally available for the soil zone. It is useful, therefore, to use clay mineral content of the vadose zone as a surrogate for CEC. A second part of the attenuation process is controlled by the availability of carbon as a catalyst for adsorption and precipitation in the medium. Thus the two key indicators used to derive the attenuation potential of the soil and unsaturated zone of the aquifer are clay mineral and organic contents.

Finally, the socio-economic value of the resource needs to be factored into the assessment. Mato (2007) suggests a scheme where the lowest status of a groundwater body is in those places where it is not used as an alternative supply, and its highest status is where there is no piped supply and groundwater is the sole source.

\subsection{SIMPLE FIELD APPROACH TO VULNERABILITY ASSESSMENT}

Taking the component parts of a groundwater vulnerability assessment identified from existing methodologies it is a relatively easy step to create a tick box approach for field use that will provide a useable vulnerability score. In order to keep the score sheet simple, some of 
Table 9.1. Identification of focus parameters for the assessment of groundwater vulnerability in the weathered basement aquifer.

\begin{tabular}{lll}
\hline Parameter & Importance & Comment \\
\hline $\begin{array}{l}\text { Degree of weathering } \\
\text { Topography }\end{array}$ & Medium & e.g. age of weathering surface \\
$\begin{array}{l}\text { Vegetation and land use } \\
\text { Soil type and cover }\end{array}$ & Medium & \\
Unsaturated zone properties & Low & Poor soils mean small influence \\
$\begin{array}{l}\text { Depth to water table } \\
\text { Clay zone present }\end{array}$ & High & Generally not known \\
Laterite present & High & Generally known \\
Organic material present & Medium & Can normally be seen in the field \\
Human dependence & Low & Generally absent in soils \\
Polluting activities & Medium & \\
& Medium & e.g. mining, livestock, fuel dumps, etc.
\end{tabular}

Table 9.2. Vulnerability scorecard-possible scores range from 4 to 30.

\begin{tabular}{llll}
\hline Parameter & Indicator & Score times bias & Score \\
\hline Topography & Flat & 0 \\
& With hollows & $3 \times 2$ \\
Depth to water table & $<5 \mathrm{~m}$ & 3 \\
& $5-10 \mathrm{~m}$ & 2 \\
& $>10 \mathrm{~m}$ & $1 \times 2$ \\
Clay zone thickness & Absent & 0 \\
& $<2 \mathrm{~m}$ & 2 \\
Degree of weathering & $>2 \mathrm{~m}$ & $3 \times 2$ \\
& Shallow $<5 \mathrm{~m}$ & 1 \\
Vegetation and land use & Thick $>5 \mathrm{~m}$ & $3 \times 1$ \\
& Sparse cover & 2 \\
& Farmland & 0 \\
Laterite present & Livestock & $1 \times 1$ \\
& Absent & 0 \\
Human dependence & Patchy & 1 \\
& Continuous & $2 \times 1$ \\
Polluting activities & Other sources & 2 \\
& None & $0 \times 1$ \\
Score $<12$ Low vulnerability & Mining & 3 \\
Score 13-22 Moderate vulnerability & Fuel dumps & 2 \\
Score $>2$ High vulnerability & $1 \times 1$ \\
\hline
\end{tabular}

the parameters can be downgraded as being least relevant to the assessment of the weathered basement aquifer. The poorly developed soils of much of the savannah lands, for example, mean that the role of these thin and sandy soils as a moderator of percolating pollutants from the surface is likely to be small. In addition the scorecard can be developed with an emphasis on those parameters that can be seen in the field rather than measured, for example, topography and slope, vegetation and land use. But the depth to the water table is a valuable parameter, as also is knowledge of clay development in the weathered zone, but 
in theory both these factors should be known in broad terms from well records or from the local drillers and well diggers.

A comprehensive list of parameters that influence groundwater vulnerability and their relevance to the basement weathered aquifer enables selection of a group of focus parameters (Table 9.1). This list suggests that the key focus parameters (high) are topography, depth to water and the presence or not of a significant clay horizon. The subordinate parameters (medium) are: degree of weathering including the fracture pattern within the less weathered bedrock, vegetation and land use, presence of laterite, livelihood dependence on the resource and the type of polluting activity. Those parameters classed as 'low' in Table 9.1 need no further consideration. The selection of the focus parameters is inevitably subjective but it does enable a reasonably well justified target set of parameters that are either known or can be seen in the field without the need for detailed measurement or monitoring.

Weighting of the parameters in terms of the focus and subordinate groups can simply be achieved by biasing the final score towards the focus parameters. The degree of bias can be determined by trial and error. Using a 100\% bias, i.e. multiplying the focus parameter scores by two, reduces the assessment to a simple field score sheet (Table 9.2). The score can range from a minimum of 4 to a maximum possible of 30 . This can be subdivided arbitrarily between high, moderate and low vulnerability to pollution as indicated on the scorecard.

\subsection{SCORECARD VALIDITY}

The validity of the scorecard, subjective and judgemental as it is, has been tested in various areas for which a detailed understanding of the prevailing conditions is available

Table 9.3. Sample scorecard for Mangochi, southern Malawi.

\begin{tabular}{|c|c|c|c|}
\hline Parameter & Indicator & Score times bias & Score \\
\hline Topography & $\begin{array}{l}\text { Flat } \\
\text { With hollows }\end{array}$ & $\begin{array}{l}0 \\
3 \times 2\end{array}$ & 0 \\
\hline Depth to water table & $\begin{array}{l}<5 \mathrm{~m} \\
5-10 \mathrm{~m} \\
>10 \mathrm{~m}\end{array}$ & $\begin{array}{l}3 \\
2 \\
1 \times 2\end{array}$ & 4 \\
\hline Clay zone thickness & $\begin{array}{l}\text { Absent } \\
<2 \mathrm{~m} \\
>2 \mathrm{~m}\end{array}$ & $\begin{array}{l}0 \\
2 \\
3 \times 2\end{array}$ & 0 \\
\hline Degree of weathering & $\begin{array}{l}\text { Shallow }<5 \mathrm{~m} \\
\text { Thick }>5 \mathrm{~m}\end{array}$ & $\begin{array}{l}1 \\
3 \times 1\end{array}$ & 3 \\
\hline Vegetation and land use & $\begin{array}{l}\text { Sparse cover } \\
\text { Farmland } \\
\text { Livestock }\end{array}$ & $\begin{array}{l}2 \\
0 \\
1 \times 1\end{array}$ & 2 \\
\hline Laterite present & $\begin{array}{l}\text { Absent } \\
\text { Patchy } \\
\text { Continuous }\end{array}$ & $\begin{array}{l}0 \\
1 \\
2 \times 1\end{array}$ & 0 \\
\hline Human dependence & $\begin{array}{l}\text { High } \\
\text { Other sources } \\
\text { None }\end{array}$ & $\begin{array}{l}2 \\
2 \\
0 \times 1\end{array}$ & 2 \\
\hline Polluting activities & $\begin{array}{l}\text { Mining } \\
\text { Fuel dumps } \\
\text { Livestock } \\
\text { Few }\end{array}$ & $\begin{array}{l}3 \\
2 \\
1 \\
0 \times 1\end{array}$ & 0 \\
\hline \multicolumn{2}{|c|}{$\begin{array}{l}\text { Score }<12 \text { Low vulnerability } \\
\text { Score } 13-22 \text { Moderate vulnerability } \\
\text { Score }>22 \text { High vulnerability }\end{array}$} & Total & 11 \\
\hline
\end{tabular}


and a perceived vulnerability rating can readily be arrived at. Using data derived from a comprehensive and well documented drilling programme at Mangochi in southern Malawi (Robins et al., 2003) a sample scorecard was derived (Table 9.3). The scorecard indicates a low vulnerability to pollution as would be expected. The score is approaching that of moderate vulnerability providing the assessment with a welcome degree of conservatism.

Similar tests for other data sets in the weathered basement aquifer provide valuable support for the methodology. However, it may be, as experience is gained with the scorecard, that the biasing factor, currently two, for the three focus parameters may require adjustment.

\subsection{CONCLUSIONS}

The valid application of quantified techniques such as DRASTIC for groundwater vulnerability assessment in the weathered basement aquifer of sub-Saharan aquifer is questionable. These techniques are data intensive as well as data selective, being developed for use in the 'North' where conditions are significantly different and where data coverage is greater.

A simple vulnerability assessment scorecard has been developed and is based on the parameters used in other assessments but requires only data that can be observed in the field. The scorecard can be used equally to assess those areas of vulnerability to polluting surface activities as well as the converse, to assess zones of greatest recharge potential. However, its main application is to help towards identifying areas where greatest care should be taken in protecting underground water resources in the weathered basement aquifer. These areas need to be recognised and safeguarded from polluting activities such as intensive cattle rearing, concentrations of people and pit latrines or even mine tailings.

The scorecard has been tested against various datasets and shown to be valid. It needs to be applied sensibly with the assessor mindful of the subjectivity of the technique. However, it is anticipated that this simple technique will provide a way forward for field assessment of groundwater vulnerability in rural and small town environments on the weathered basement aquifer.

\section{REFERENCES}

Adelana, S.M. \& MacDonald, A.M. (Eds.) 2008. Applied Groundwater studies in Africa. International Association of Hydrogeologists, Selected Papers, 13, CRC Press/Balkema, London.

Aller, L., Bennett, T., Lehr, J.H., Petty, R.J. \& Hackett, G. 1987. DRASTIC: a standardised system for evaluating groundwater pollution potential using hydrogeological settings. US-EPA Report 600/2-87-035.

Calow, R.C., MacDonald, A.M., Nicol, A.L. \& Robins, N.S. In press. Groundwater and drought in Africa - the balance between water availability, access and demand. Ground Water.

Daly, D. \& Warren, W.P. 1998. Mapping groundwater vulnerability: the Irish perspective. In: N.S. Robins (Ed.) Groundwater Pollution, Aquifer Recharge and Vulnerability. Geological Society Special Publications, 130, 179-190.

Davies, J. \& Robins, N.S. 2007. Groundwater occurrence north of the Limpopo: are erosion surfaces the key? Geological Society of South Africa Groundwater Division Groundwater Conference, Bloemfontein (CD).

Foster, S.S.D. 1998. Groundwater recharge and pollution vulnerability of British aquifers: a critical overview. In: N.S. Robins (Ed.) Groundwater Pollution, Aquifer Recharge and Vulnerability. Geological Society Special Publications, 130, 7-22.

Griffiths, K.J., MacDonald, A.M., Robins, N.S., Merritt, J., Booth, S.J., Johnson, D. \& McConvey, P. In press. Improving the characterisation of Quaternary Deposits for groundwater vulnerability assessments. Quarterly Journal of Engineering Geology \& Hydrogeology.

MacDonald, A.M., Davies, J., Calow, R. \& Chilton, J. 2005. Developing Groundwater, a Guide for Rural Water Supply. ITDG Publishing, Warwickshire, UK. 
Mato, R.R.A.M. 2007. Modeling and mapping groundwater protection priorities using GIS: the case of the Dar Es Salaam city, Tanzania. In: Witkowski, A.J., Kowalczyk, A. \& Vrba, J. (Eds.) Groundwater Vulnerability Assessment and Mapping. International Association of Hydrogeologists Selected Papers 11, 155-166.

Palmer, R.C., Holman, I.P., Robins, N.S. \& Lewis, M.A. 1995. Guide to Groundwater Vulnerability Mapping in England and Wales. HMSO, London.

Robins, N.S., Adams, B., Foster, S. \& Palmer, R.C. 1994. Groundwater vulnerability mapping: the British perspective. Hydrogéologie, 3, 35-42.

Robins, N.S., Davies, J., Hankin, P. \& Sauer, D. 2003. Groundwater and data: an African experience. Waterlines, 21: 4, 19-21.

Robins, N.S., Chilton, P.J. \& Cobbing, J.E. 2007. Adapting existing experience with aquifer vulnerability and groundwater protection in Africa. Journal of African Earth Sciences, 47, 30-38. 